\title{
Convencionalismo ético en deporte D’Agostino y Morgan en torno a las reglas y convenciones en deporte
}

\author{
RAÚl FRANCISCO SEBASTIÁN SOLANES \\ Universidad de Valencia (España) \\ Raul.Sebastian@uv.es \\ VÍCTOR PÁRAMO VALERO \\ Universidad de Valencia (España) \\ Vicpava@alumni.uv.es
}

\begin{abstract}
Resumen
En el presente artículo nos proponemos realizar una comparación de la posición de D'Agostino con la de otro de los representantes del convencionalismo: William Morgan. A D'Agostino nos referiremos en el primer apartado y a Morgan en el segundo. Nos preguntaremos si Morgan, además de inscribir sus tesis dentro del convencionalismo, participa al mismo tiempo de la concepción internalista del deporte. Aunque uno y otro autor son convencionalistas, existen matices muy distintos entre sus posiciones que caben ser resaltadas, a fin de clarificar su proximidad con otras teorías filosófico-deportivas.
\end{abstract}

Palabras claves: convencionalismo ético, internalismo, ética del deporte.

\section{Ethical convention in sport D'Agostino and Morgan about the rules and conventions in sport}

\begin{abstract}
In this paper we propose a comparison of the position of D'Agostino with other representatives of convention: William Morgan. We refer to D'Agostino's position in the first section and in the second section to Morgan's. We ask whether Morgan, moreover of register his thesis within the Conventionalism, participates also of the internalist conception of sport. Although both authors are conventionalists, there are many different shades that fit between their positions be bighlighted, in order to clarify its proximity to other philosophical theories of sport.
\end{abstract}

Key words: ethical convention, internalism, sports ethics.

Doctor Europeo en Sociología por la Universidad de Bolonia. Doctorando en Filosofía en la Universidad de Valencia con la dirección de Adela Cortina. Entre sus últimas publicaciones cabe destacar: "Horizonte y necesidad de una economía ética en deporte" (2012), "Deporte y migración: Las diferencias sociológicas de género en deporte, desde la ética" (2012) y "Ética del deporte" (2013). 


\section{Introducción. El convencionalismo ético en deporte}

Gilles Lipovetsky considera que en nuestra época predomina una moral débil, una ética indolora, que no exige el cumplimiento con imperativos, ni tampoco acciones virtuosas, sino únicamente el logro del placer y la erradicación del dolor, la adopción de códigos morales que no exijan sacrificio alguno, donde la lógica del don se sustituye por la lógica del intercambio y donde la ética del deber se sustituye por la deontología, el pragmatismo y el utilitarismo. En esta época, la moral que se ve profundamente afectada por las condiciones económicas y políticas de una democracia de masas como la que existe en la mayoría de las naciones occidentales (Brohm, 1992). La economía capitalista se impone en todas las esferas de la sociedad, transformando la vida de las personas. Lo que sucede en la sociedad se refleja en un gran número de ámbitos que se superponen en la sociedad, ámbitos tales como la sanidad, el ocio o el deporte. Este último, en particular, ha sido metamorfoseado por la lógica capitalista de la comercialización (Lipovetsky, 1994: 114-115).

A pesar de este momento post-moralista del deporte denunciado por Lipovetsky, que coincide con el culto hiperbólico del espectáculo, con la estrategia de comunicación de marcas, con la personalización de los campeones; y a pesar de que el deporte bien podría estar dentro de la racionalidad de lo efímero y lo frívolo donde la objetividad se instituye en espectáculo y la dominación técnica se reconcilia con lo lúdico (Lipovetsky, 2011: 18) el deporte sigue siendo el mejor trasmisor de valores morales en una sociedad en crisis axiológica. Ello ha contribuido a que desde el ámbito filosófico contemporáneo se haya concedido importancia al deporte. Hasta hace algunos años el deporte no había sido objeto de estudio académico en ninguna de las áreas científicas que existen en la actualidad. Tan solo habían existido estudios marginales, aunque fundamentales, a partir de los cuales han surgido, aunque con gran posterioridad, estudios dedicados a problemas cada vez más específicos. La visión general que antaño se tenía se ha perdido debido a la lógica de la investigación científica, que necesita diseccionar por completo la realidad para explicarla. En el campo de la ética del deporte ha sucedido algo similar. Se considera que es un ámbito científico como los demás (derecho deportivo, sociología deportiva, biología deportiva, medicina deportiva, etcétera). Uno de los problemas que, pese a la especialización, no ha podido generar un acuerdo mutuo entre los distintos investigadores y en torno al cual siguen existiendo múltiples debates es el problema de las reglas deportivas y su relación con los valores e ideales morales. En torno al él discuten actualmente «convencionalistas», «internalistas»y 
«formalistas», así como otras versiones de estas posiciones filosóficas fundamentales.

Algunos autores como el profesor Agustín Domingo Moratalla han señalado acertadamente que pese al momento post-moral o la llegada de una filosofía «más allá del bien y del mal» siguen cabiendo interpretaciones que salven al sujeto y a la maltrecha filosofía moral que arranca con fuerza con el «giro aplicado». Se trata de un nuevo reto aplicado para la ética que se hace necesario para el deporte, pues la sensibilidad para la aplicación ya no se les exige sólo a los expertos, sino que se nos exige a todos (Domingo Moratalla, 2014: 94-95).

Adela Cortina ha señalado que el deporte es un fenómeno social propio de todas las épocas y culturas que con el tiempo gana la implantación social. Debido a los múltiples problemas que surgen en torno al fenómeno deportivo surge un nuevo saber, la ética del deporte, que intenta enfrentarse a temas de envergadura, desde el dopaje, la comercialización, la violencia gratuita y otros muchos (Cortina, 2014: 25). Esto explica como desde los años 70 del pasado siglo XX se tomaran multitud de iniciativas que tuvieron como consecuencia el surgimiento de la filosofía y ética del deporte enlazando con el reto aplicado.

Un hecho importante en el surgimiento y posterior auge de la filosofía y ética del deporte tiene lugar el año 1972 en el ámbito estadounidense. En ese año la American Philosophical Association de Boston funda el 28 de diciembre la Philosophic Society for the Study of Sport (PSSS) con el principal respaldo y esfuerzo de Warren P. Fraleigh de la State University of Brockfort y de Paul Weiss de la Catholic University. A partir de 1999 la PSSS pasa a llamarse definitivamente como International Association for Philosophy of Sport. Desde esta Asociación se empezó a publicar el Journal of the Philosophy of Sport que comienza con una publicación anual desde 1974 y bianual desde al año 2001 (Macnamme, 2007).

El paso definitivo de la filosofía a la ética del deporte se produce a finales de los años ochenta y principios de los noventa del pasado siglo XX. Dos hechos importantes para esta transición serán la publicación en 1981 del libro de Alasdair MacIntyre After virtue que marcará la dirección que siguen muchas de las propuestas ético-deportivas de estos autores. El segundo hecho será, la publicación en 1991 del libro de Robert Louis Simon Fair play: Sport, V alues and Society, reimpreso en 2004 y 2006 con el nombre de Fair play: The ethics of sport. En este libro Simon se refiere expresamente no a una filosofía o sociología del deporte, sino a una propuesta de competition ethics. Estos acontecimientos coinciden con el denominado «giro aplicado» en ética y la consolidación de la Ética Aplicada, atraída por la urgencia de los problemas y la gravedad de los conflictos 
que requieren de una inmediata respuesta (Domingo Moratalla, 2014: 96).

Progresivamente surgirán las nuevas corrientes de ética del deporte en el contexto norteamericano como el Formalismo ético iniciado por Warren P. Fraleigh autor del importante libro Right actions in sport publicado en 1984, las éticas del deporte como «bolsas de virtudes» que ofrecen Ángela Lumpkin, Sharon K. Stoll y Jennifer. M. Beller en su libro colectivo Sport ethics: applications for Fair Play y la propuesta que realizaron Brenda Jo Light Bredemeier y David Lyle Light Shields en su libro Character Development and Physical Activity. De gran importancia es el el Internalismo ético de Robert Butcher y Angela Schneider, junto al elaborado por Robert. Louis Simon y junto a esta corriente destaca el Convencionalismo ético con importantes representantes como son D'Agostino y William Morgan.

$\mathrm{Al}$ primero se lo considera el padre del convencionalismo, sobre todo gracias a su pionero artículo "The Ethos of Games", al que citaremos más adelante. La posición del segundo ha sido definida como convencionalista. Nos preguntaremos si Morgan, además de inscribir sus tesis dentro del convencionalismo, participa al mismo tiempo de la concepción internalista del deporte. A D'Agostino nos referiremos en el primer apartado y a Morgan en el segundo. Nos proponemos realizar una comparación de las posiciones de ambos autores. A pesar de que los dos son convencionalistas, existen matices muy distintos entre sus posiciones que caben ser resaltadas, a fin de clarificar su proximidad con otras teorías filosófico-deportivas.

El convencionalismo ético es una de las manifestaciones del externalismo ético que Robert L. Simon se ha propuesto superar. Ha presentado una posición alternativa. Los partidarios del convencionalismo ético en deporte, con D'Agostino al frente, marcan distancias con los presupuestos teóricos del formalismo ético. Si los partidarios del formalismo ético en deporte ponían énfasis en la importancia de cumplir con lo establecido por las reglas constitutivas, sin salir del marco regulativo establecido por los códigos deportivos, dentro de los cuales — según afirman- debe transcurrir siempre la acción - pues las reglas son las que definen la naturaleza misma del deporte (sin reglas no hay deporte)-, para los defensores del convencionalismo ético lo que define la naturaleza de éste son los convenios sociales, que en última instancia deciden qué es lo que está bien o mal en la práctica deportiva y que constituye la base de lo que D'Agostino ha convenido en denominar su «êthos del juego».

La actitud de los partidarios del convencionalismo ético hacia el uso de trampas o de faltas estratégicas es mucho más permisiva, pues no se las ve como la principal amenaza para romper con el lado ético de la 
práctica deportiva, además de no ser las responsables de la vulneración de la naturaleza, como sí sostienen los formalistas. Esto se debe a que los convencionalistas estarían dispuestos a sostener que este tipo de recursos, como son las faltas estratégicas, se dan en deporte porque existe un convenio social que permite que en un deporte (especialmente en el baloncesto) se produzcan este tipo de faltas, que son vistas como un movimiento estratégico legítimo dentro de este juego y que, por tanto, están dentro de lo éticamente aceptable dentro de la óptica del denominado «êthos del juego».

Por ello, para los convencionalistas clásicos las faltas estratégicas deben ser entendidas como un tipo de faltas que vulneran la moralidad que debe gobernar a las acciones que llevan a cabo los deportistas, cuyas faltas que descalifican a todo aquel se sirve de ellas para lograr un beneficio que no infringe el código deportivo. A pesar de que no violen reglas deportivas, las faltas estratégicas disminuyen la cualidad moral de las acciones deportivas y, en consecuencia, deben ser penalizadas, al menos desde el punto de vista ético. El hecho de que el reglamento no contempla la penalización de este tipo de acciones no puede constituir en modo alguno un argumento en contra de la sanción y descalificación éticas de esta clase de acciones. En suma, aunque no sean antireglamentarias, son acciones inmorales y, como tales, deben ser detectadas y vituperadas.

Simon piensa que las versiones más recientes del convencionalismo han realizado una gran contribución a la actual comprensión de la naturaleza de la práctica deportiva. Han explotado el papel que el contexto social y cultural juega dentro del deporte y han mostrado su conexión con la ética que es necesaria en éste. Sin embargo, Simon no puede aceptar los presupuestos del convencionalismo ético debido a que ve un importante problema en esta corriente filosófica. Considera que no logra definir adecuadamente las convenciones o convenios sociales. En efecto, el convencionalismo ético no define la condición ética de los propios convenios: por ejemplo, no detalla cuáles son los convenios sociales a causa de los cuales faltas las faltas estratégicas son socialmente aceptadas.

Por ello, Simon entiende que el convencionalismo ético se asemeja al denominado «relativismo cultural normativo», que establece que las personas deben seguir las normas morales dominantes en sus propias culturas, entendiendo que en cada cultura existen unas normas morales dominantes diferentes a las de otras culturas (Simon, 2000: 39). Los partidarios del «relativismo cultural normativo» sugieren que la aparición de reformadores de las normas culturales dominantes en una cultura tiene efectos negativos en la cultura en cuestión. Del mismo modo, el convencionalismo ético, al igual que esta forma de relativismo cultural a la que según Simon es afín, defiende una postura que se aproxima al reduccio- 
nismo ético en deporte, del que Simon se propone distanciarse (Simon, 1991: 199).

En definitiva, al hacer hincapié en la configuración social e histórica del deporte, el convencionalismo acepta situándolo dentro de un contexto socio-cultural. El problema de esta posición está en que ha permanecido en la superficie, centrándose demasiado en los convenios socioculturales específicos del deporte, sin profundizar en la naturaleza de los mismos y en los recursos culturales disponibles. El Convencionalismo, según Simon, no está en condiciones de enfrentarse a cuestiones como la deportividad (Sportmanship) o la naturaleza de las violaciones estratégicas de las reglas del juego.

De aquí se explica la necesidad de Simon de componer una ética que entiende que además de las reglas constitutivas del deporte, o que además de los convenios socio-culturales en el deporte, existen unos valores morales internos a la práctica deportiva, comunes, no sólo específicos, a todas las culturas, considerando que la meta de la dicha práctica debe de ser la búsqueda mutua de la excelencia moral a través de la observancia de reglas y de la búsqueda de la equidad (Simon, 2000: 40). El internalismo ético de Simon intenta explicar de forma distinta al convencionalismo el uso de las faltas estratégicas y la posibilidad de cambios en las reglas constitutivas del deporte (Simon, 2000: 45).

Consideramos que la visión que Simon tiene del convencionalismo es harto reduccionista. En lo que sigue intentaremos mostrar la riqueza del convencionalismo y su valiosa aportación a la filosofía del deporte. Para ello, nos centraremos en dos autores que, aunque mantiene puntos de vista distintos, se encuentran ambos dentro del convencionalismo. Se trata de Fred D'Agostino y William Morgan. Este último reconoce ser heredero de la posición de D'Agostino, aunque introduce nuevas ideas e incluso se distancia de este en algunas cuestiones centrales.

\section{El êthos del juego como conjunto de convenciones según Fred D’Agostino}

El artículo de Fred D'Agostino titulado "The Ethos of Games" constituye uno de los más importantes dentro de la tradición de ética del deporte denominada «convencionalismo». Es considerado como uno de los escritos fundadores de esta posición ética. Fue publicado en 1981 en la revista Journal of the Philosophy of Sport. En la década de los años ochenta la filosofía del deporte se había comenzado a desarrollar y era el momento en que surgirían otras corrientes ético-deportivas alternativas. El convencionalismo se presenta como una posición alternativa a la del formalismo ético. 
Aunque D’Agostino no hace referencia a los filósofos morales clásicos que han empleado el concepto de êthos (desde Aristóteles hasta Kant), dicha noción está impregnada de la tradición filosófica. La palabra êthos en griego clásico puede ir con épsilon («e» breve) o sin épsilon (con «etha», «e» larga). En el primer caso significa «costumbre», «hábito». Ethos con «etha» refiere a una forma de ser, y tiene relación con el término latino «more», morada. Parece que D'Agostino se refiere al primer caso. Al hablar de «êthos del juego» no se refiere, por tanto, al hecho de que las reglas del juego no determinan lo que está permitido y lo que no está permitido en el juego; lo que determina la permisión y no permisión es la interpretación de la circunstancia concreta, tomando como referencia las reglas pero también el êthos. Éste puede sobreponerse a las reglas cuando éstas entran en contradicción con él.

El formalismo defiende que 1) las reglas del deporte son la esencia del deporte; es decir, que lo determinante para que el deporte sea posible es la existencia de reglas. De ello se deriva una segunda tesis: 2) Si quienes participan en un juego o en un deporte se atienen a las reglas, se habrán comportado éticamente. Será jugadores o deportistas éticos. Como ya señaló Wittgenstein en sus Investigaciones filosóficas, todo juego se define por sus reglas (Wittgenstein, 2011: \ 7-30). Sin reglas no hay propiamente juego. El juego es resultado de la aplicación de un conjunto determinado de reglas. ¿Existe algún juego que no posea reglas? No. Y, en caso de haberlo, no debe ser denominado «juego».

D’Agostino no habla propiamente de prácticas deportivas, ni tampoco del deporte de alta competición. Se refiere exclusivamente a los juegos deportivos para defender la tesis expuesta. Juego es todo aquello que posee un êthos y reglas formales (D'Agostino, 1981: 7). El êthos de un juego es el «conjunto de convenciones que determinan cómo sus reglas deben ser aplicadas en circunstancias concretas» (D'Agostino, 1981: 15).

Desde el principio D'Agostino quiere desmarcarse de la propuesta formalista que desarrollan importantes autores como Warren. P. Fraleigh. La premisa básica del formalismo afirma que no hay deporte sin reglas formales. El formalismo entiende que «jugar a $G$ » equivale a «seguir las reglas formales de $G$ », donde «G» es un juego cualquiera (D’Agostino, 1981: 7). D'Agostino realiza dos críticas fundamentales al formalismo. Lo acusa, en primer lugar, de tener implicaciones idealistas, en el sentido platónico. En segundo lugar, señala que la explicación formalista de las sanciones es inadecuada. El formalismo entiende que las acciones que son penalizadas por las reglas convierten ipso facto al individuo que las comete en alguien no capacitado para el juego. Nos centraremos en esta segunda acusación. Siguiendo a D'Agostino, podemos señalar que, por ejemplo en el baloncesto, además de existir continua- 
mente algo que niega lo que las reglas dictan (el contacto entre los jugadores), no siempre se señalan las infracciones que se han cometen. ¿Por qué los árbitros deciden dejar continuar el juego? D'Agostino expone que, en algunos casos, la justificación de esa decisión reside en el êthos del juego. El árbitro tiene legitimidad para dejar continuar el juego cuando la acción cometida no va en contra del êthos del juego.

Cuando las infracciones no impiden que el equipo perjudicado por ellas pueda seguir progresando en el juego, los árbitros nos las señalan, al menos en algunas ocasiones. Entre las reglas del deporte se incluyen las sanciones. Éstas están destinadas a penalizar la infracción de las reglas. Es decir, son una clase específica de reglas dirigida contra la infracción de las reglas. Parece que los árbitros infringen las propias reglas al no señalar algo que las reglas dicen que es una infracción. Pero en realidad la permisión que hacen los árbitros está destinada a que el juego se desarrolle correctamente, es decir, al no señalar una infracción y penalizarla intentan que el juego tenga lugar como los jugadores y los espectadores esperan. Esto significa que la no aplicación de las reglas no equivale a dejar de jugar al juego en cuestión. Añadimos, pues, junto a D’Agostino, otro argumento contra la tesis principal del formalismo: la no aplicación de las reglas específicas que penalizan la violación de las reglas es una forma de hacer que el juego se desarrolle mejor.

$\mathrm{Si}$, según las reglas, el baloncesto es un deporte de «no contacto», no por ello el baloncesto es un deporte de no contacto. El problema del formalismo es que permanece aislado de la práctica real del deporte y cree que éste solo puede ser comprendido por lo que las reglas formales dicen de él. El formalismo defiende que si las reglas establecen que en el baloncesto no puede haber contacto directo entre los jugadores, en el caso de que tenga lugar dicho contacto a lo que juegan los jugadores no es en realidad baloncesto. Para jugar al baloncesto hay que seguir sus reglas. Cometer una infracción equivale a dejar de jugar al deporte en cuestión. Parece que los formalistas no estarían dispuestos a admitir que de su concepción del deporte se derive esta paradoja. D’Agostino se encarga de mostrar que en efecto sí es así, y si nos atenemos a las tesis básicas del formalismo, no hay modo de evitar las conclusiones a las que nos hemos referido. La tensión entre las reglas del deporte y la práctica real del mismo no es algo inhabitual. En realidad, sin esa tensión no se desarollaría cada partido o competición en particular. La práctica del deporte presupone que hay una tensión entre las reglas (que tienen, por naturaleza, un carácter general) y su aplicación a situaciones concretas.

El título del trabajo de D'Agostino enuncia su propuesta: sustituir la explicación del deporte y de sus condiciones de posibilidad por referencia a las reglas por una explicación en la que se dé cuenta del hecho de 
que hay excepciones a la regla y de que la realización de tales excepciones es legítima.

D'Agostino cree que la dualidad formalista «permitido»/«no permitido», que equivale, «jugar a un $G$ »/«no jugar a un juego G» hace que la explicación del deporte sea excesivamente reduccionista y no pueda dar cuenta realmente de por qué un jugador sí juega a un juego $G$ aunque no cumpla algunas de sus reglas e incluso tenga razones morales para incumplirlas. La propuesta de D'Agostino de un ethos del juego deportivo permite distinguir entre: 1) el comportamiento de los jugadores que es permisible (no es sancionado por las reglas); 2) el comportamiento que las reglas no permiten pero que es aceptable; c) el comportamiento que es inaceptable.

D'Agostino denomina «convenciones» a el conjunto de razones morales que hacen de una acción aceptable a pesar de que vaya en contra de las reglas formales del juego. Las razones morales se extraen del ethos. Uno tiene razones para cometer una infracción —es decir, uno tiene legitimidad para hacerlo y, por tanto, su acción es aceptable - cuando actúa de acuerdo con el ethos del juego. Las convenciones, por tanto, se adoptan durante el juego y hacen referencia a los actos que aunque no están permitidos por las reglas son aceptables. De modo que no todo depende de lo que las reglas señalan. D’Agostino entiende que su explicación del juego se distancia de la formalista porque está liberada de la dualidad permitido por las reglas/no permitido por las reglas. Incluso, la noción de «permisión» que él emplea es diferente de la formalista. Añade a lo que «está permitido» en el juego un matiz importante con respecto al formalismo:

Permissible behavior is, on this nonformalist account of games, either in accordance with the formal rules of a game or violates those rules only in a way which, according to the ethos of that game, does not require the invocation of penalties (D'Agostino, 1981: 15).

Precisamente la defensa de que estas acciones que violan las reglas no deben ser sancionadas y de que, según el êthos, deben permitirse -es decir, a la apelación a una dimensión que se encuentra más allá de las reglas, una dimensión que aquí es enunciada como êthos y que hace referencia (como vimos al comienzo) no a una concepción filosófico-moral, sino únicamente a intuiciones morales, a aquello que los jugadores y los espectadores estarían dispuestos a admitir como permisible a pesar de que las reglas digan lo contrario-, es a lo que se ha denominado convencionalismo.

El convencionalismo tiene en cuenta siempre la situación concreta en la que las reglas deben o no aplicarse. En función de lo que ocurre en esa situación se entiende que es adecuado o no aplicar las reglas. 
D’Agostino introduce la idea de que lo que debe estar permitido no depende únicamente de lo que las reglas dicen. La permisión de determinados actos debe realizarse también en función de lo que el êthos nos dice. Por ello, lo que está permitido en el desarrollo del juego no se reduce a una dimensión legal o jurídica; debe tenerse en cuenta también una dimensión moral. Ésta puede ser una moral que Kant denominó «vulgar», no depurada por la razón (Kant, 2003), en el sentido de que las nociones de que se compone no han sido analizadas ni validadas por la razón, sino que proceden de lo que se entiende vulgarmente como moral. Esto puede, a su vez, depender de la sociedad, tradición o cultura en la que dicha moral se ha forjado, pero también de una moral ingenua intuicionista, que, como han mostrado recientemente los neuroeticistas, tiene base cerebral, pero que no por ello no puede dejar de ser educada (Cortina, 2011).

D’Agostino recupera dos ideas fundamentales de la tradición filosófico-moral aristotélica: 1) la idea de phrónesis, una saber práctico que se convierte en virtud (areté) cuando es cultivada adecuadamente, una virtud que deben poseer sobre todo los gobernantes de la ciudad (polis). Se trata de un saber eminentemente práctico, es decir, que se aplica a situaciones particulares. 2) En este sentido, D'Agostino da una importancia radical a aquello a lo que las leyes o reglas no alcanzan por su propio carácter general. Aristóteles ya había señalado, en sus obras de ética, la importancia de contar con la situación particular, donde lo que D'Agostino denomina êthos debe jugar un papel esencial: êthos, como vimos, es la palabra griega para enunciar el hábito, la costumbre. El phrónimos es el que ha cultivado la virtud de la phrónesis. Es el que sabe actuar en cada situación como debe. Aristóteles entendía que el juez debía ser una extensión de la ley, pero en el sentido de que debía saber ponderar adecuadamente lo que convenía a la situación a la que aquélla no alcanza por su carácter general. El juez actúa de forma diferente a la ley, ya que cuenta con la situación concreta. Y el juez que posee la virtud de la phrónesis actúa adecuadamente. D'Agostino conecta con esta idea fundamental de la ética aristotélica, aunque no lo hace explícito; en realidad, no necesita hacerlo, pues el hecho mismo de tomar el término «êthos del juego» para enunciar su propuesta deja ver esta deuda con la ética de Aristóteles. Hacer justicia allí donde la ley no puede hacerla es la función del juez. Del mismo modo, el árbitro tiene que actuar contando con la ley pero no siempre haciendo lo que ella dicta, ya que es posible que, según sus conocimientos prácticos, sea justo no sancionar al jugado que realiza una acción que está penalizada por las reglas. En este sentido, el árbitro actúa como el juez aristotélico: el buen árbitro es, como el buen juez, el versado en la phrónesis, el que 
tiene conocimientos prácticos morales y puede dejar seguir el juego en nombre del ethos, que está por encima de la ley (Pérez Triviño, 2013a).

Hemos delimitado lo que D’Agostino considera permisible dentro del juego. Cree que lo impermisible no es sólo aquello que las reglas dicen que es impermisible, sino aquello que, cuando éstas dicen que es impermisible, el êthos exige, apoyando las reglas, una sanción a los actos cometidos. En efecto, lo que no está permitido no es lo que las reglas dicen que es impermisible, sino esto más su aprobación por el êthos, el cual puede ser tanto el juicio moral basado en la educación como el juicio moral que se realiza por intuiciones. El êthos del que habla D’Agostino debe estar presente tanto en lo que está permitido como en lo que no lo está.

El tercer punto enunciado (recordemos: primero, el comportamiento que está permitido por las reglas; segundo, el comportamiento que no está permitido por las reglas pero que es aceptable según el êthos del juego), el comportamiento que es inaceptable según el êthos del juego y no está permitido por las reglas, sí constituye un punto de concordancia entre la explicación formalista y la explicación convencionalista. Para el convencionalismo, el que comete una acción inaceptable no debe ser considerado como un jugador. Lo mismo opina el formalismo: el que incumple las reglas del juego no es propiamente jugador del juego (Fraleigh, 1984: 73; Fraleigh, 2003: 211). Lo que quizá diferencia, aunque constituya sólo un matiz, a ambas explicaciones es la razón por la cual consideran que los actos cometidos hacen que el individuo en cuestión no sea propiamente jugador del juego. El convencionalismo entiende que las acciones inaceptables hacen que «sea descalificado a quien las comete como jugador del juego» (D’Agostino, 1981: 14) porque van en contra del êthos el juego. El formalismo afirma que el individuo ha de ser descalificado y considerado como no jugador porque incumple las reglas del juego. Podemos observar cómo la posición convencionalista mantiene siempre la referencia al êthos. Lo decisivo, por tanto, de las acciones de los jugadores, según el convencionalismo, es si se encuentran de acuerdo o no con este êthos.

D’Agostino cree que la explicación formalista del juego es inadecuada precisamente por ignorar la dimensión ética. No se puede explicar la relación del juego con lo que está permitido/no permitido en él sin la apelación al ethos. Por tanto, el juego deportivo y la ética están íntimamente vinculados. D'Agostino no da en el artículo citado el nombre de «convencionalismo» a la posición «no formalista» que expone en su artículo. Sin embargo, la importancia que otorga a la situación particular y al ethos del juego - entendido como conjunto de convenciones- establece la base de esta concepción. Lo que resulta más importante de su críti- 
ca al formalismo es su apelación a las convenciones. Sobre todo resulta importante para entender la deriva que ha tomado posteriormente el convencionalismo.

A continuación examinaremos los puntos de conexión que existen entre el convencionalismo de D'Agostino y la concepción de William Morgan que denominaremos como «convencionalismo internalista».

\section{E1 convencionalismo internalista de William Morgan}

\subsection{Entre convencionalismo e internalismo}

En esta sección del artículo, continuando con la argumentación enunciada al comienzo, vamos a exponer cuáles son las características de la posición de William Morgan y a mostrar su proximidad con las de la posición de Fred D'Agostino. Lejos de entender teoría del deporte de Morgan como parte del internalismo en sentido amplio (broad internalism) o interpretativismo (una teoría normativa del deporte defendida por autores de gran renombre como R. Simon, autor del célebre libro Fair Play. The Ethics of Sport), mostraremos que defiende ideas propias del convencionalismo, aunque no en su versión clásica.

Una explicación normativa de la práctica del deporte puede incurrir, al menos, en dos errores. El primero consiste en que la explicación normativa intenta averiguar qué es lo deseable en todo caso, y no en este o aquél, y cuando cree haberlo averiguado asegura disponer de legitimidad para establecer cómo debe transcurrir dicha práctica. Al mismo tiempo, y en segundo lugar, prescinde de la práctica real (la que tiene lugar en cada caso) para abstraer o extraer de ella una práctica ideal prototípica (que no es todavía la práctica ideal normativa) a la que toma como referencia para después establecer lo que es necesario en ella y que debe instituirse en forma de normas. Toda teoría normativa del deporte no solo extrae el deber del ser (formula normas a partir de una realidad deportiva que es, no obstante, reducida o mutilada, una realidad que es tomada siempre parcialmente, ya que la referencia la constituye siempre un caso ideal prototípico, como lo hemos denominado). El deporte, como práctica humana que tiene lugar en un entramado de dimensiones cognitivas (moral, social, económica, psicológica, etcétera) que afectan directa y simultáneamente al deportista, debe ser comprendido en su práctica real, y no en la práctica.

$\mathrm{Al}$ mismo tiempo, valores internos a la práctica deportiva son aquellos que pertenecen única y exclusivamente a dicha práctica y no han sido tomados del grupo de valores existentes en la sociedad en que se desarrolla la práctica deportiva. Se trata de valores que no han sido traslada- 
dos desde la sociedad al deporte. Dichos valores que le pertenecen de manera exclusiva al deporte no existían propiamente en la sociedad, tan solo se desarrollan adecuadamente en la práctica del deporte. Esta clase de valores se diferencia de los que sí han sido trasladados de la sociedad al ámbito del deporte (los cuales pueden ser denominados «valores externos a la práctica deportiva»).

El convencionalismo se encuentra entre los principales rivales del internalismo en sentido amplio. Ésta es una de las teorías más relevantes dentro de la filosofía del deporte. Afirma que en la práctica deportiva -en cualquiera de sus niveles (amateur, profesional, élite), en cualquiera de sus versiones (deportes de equipo, deportes individuales, etcétera) y en cualquiera de sus fases (entrenamiento, competición, etcétera)- existen valores. Por el hecho de ser deportiva una práctica posee ya valores intrínsecamente. Esto significa que ninguna práctica deportiva puede ser comprendida al margen de sus valores. En caso contrario, se comprende parcialmente a la práctica deportiva en cuestión. El internalismo es una teoría normativa en tanto en cuanto no se limita únicamente a describir los valores que forman parte de la práctica deportiva, sino que al mismo tiempo prescribe cuáles deben ser tales valores. $\mathrm{Al}$ analizar la práctica real del deporte se encuentra habitualmente que no respetan o promueven los valores que deberían estar presentes en ella. De ahí que sea necesario establecer cuáles son los valores de los cuales cada práctica deportiva no puede prescindir.

\subsection{Una precisión necesaria}

La concepción que D’Agostino desarrolla de las convenciones es diferente de la de Morgan. Las deep conventions son distintas de las convenciones de las que habla D'Agostino. Por tanto, aunque ambos son convencionalistas, hay una diferencia fundamental entre ambos. No obstante, dicha diferencia no mina nuestro argumento, pues según consideramos, el pensamiento de Morgan es convencionalista en un sentido próximo al de D'Agostino y no «convencionalista internalista». Tan solo nos obliga a matizar lo que hemos afirmado: aunque Morgan se distancia en este punto fundamental de la posición de D'Agostino, sigue siendo convencionalista. Por ello, la referencia a D'Agostino en realidad sigue siendo necesaria, aunque sea únicamente para señalar el sentido que tiene la oposición que hace Morgan contra el internalismo y el formalismo. En su artículo Morgan reconoce y expone cómo el internalismo ha constituido un gran avance con respecto al formalismo, cosa que en el artículo de D'Agostino considerado todavía no puede hacerse, ya que la teoría internalista se desarrollará más tarde en sus puntos fundamentales con la 
obra de Robert Louis Simon o Robert Butcher y Angela Schneider. La distanciación del formalismo es explícita tanto en el artículo de D'Agostino como en el de Morgan. Si hay algo que matizar es, como hemos indicado, que Morgan concibe a las «deep conventions» de forma diferente a lo que D'Agostino entiende por «ethos of games». Una de las diferencias fundamentales entre ambas concepciones, señalada por el propio Morgan, consiste en que en el «Ethos of games» de D'Agostino «el estatus normativo de una convención permanece «enteramente» en su aceptación social, en la que los individuos pueden sostenerlas o no, como opuestos a las consideraciones intelectuales a su favor» (Morgan, 2012: 79). La concepción de D’Agostino se asemeja a lo que David Lewis había denominado «coordinating conventions» (Morgan, 2012: 66). Existen otras diferencias entre las concepciones que ambos autores tienen de las convenciones. Esto no constituye, como hemos indicado, una refutación de nuestro argumento. Al exponer la posición de D’Agostino teníamos únicamente como propósito disponer de una exposición clásica de las tesis convencionalistas, a fin de entender mejor la posición de Morgan. Sin duda, como veremos también a continuación, hay diferencias entre la posición de D'Agostino y el de Morgan, pero ambos comparten ideas que les hacen merecedores del apelativo «convencionalista».

\subsection{Internalismo y convencionalismo}

El internalismo en sentido amplio, que Morgan denomina siguiendo a Robert L. Simon, broad internalism, ofrece una explicación de la naturaleza del deporte y de sus condiciones de posibilidad distinta de la que propone el convencionalismo. Morgan se separa del internalismo de Simon (Morgan, 2012: 70) principalmente porque considera que, a pesar de que es una posición más sólida que el formalismo y de ser, incluso, a su juicio, la teoría normativa del deporte más importante existente en la actualidad (Morgan, 2012: 65). Las convenciones sociales de cualquier clase sí tienen cabida en una explicación normativa del deporte. Esto significa que el convencionalismo que defiende Morgan, lejos de hacer de los principios inherentes al deporte el fundamento de su explicación normativa, cree que debe incorporarse también al selecto grupo de elementos normativos que explican la naturaleza y las condiciones de posibilidad del deporte, las convenciones que se encuentran en la sociedad y que afectan de uno u otro modo al deporte. Para el internalismo los principios en que se basa la explicación normativa del deporte (es decir, los juicios normativos concernientes a su naturaleza) no pueden ser, en ningún caso, convenciones sociales (Morgan, 2012: 67). La diferencia fundamental entre uno y otro planteamiento filosófico reside en que el 
internalismo considera que los juicios se derivan directamente de consideraciones intelectuales que no atienden ni se ven afectadas por el contexto histórico o social en que son formuladas. Por el contrario, el convencionalismo cree que el contexto es decisivo: las convenciones sociales son la base de los juicios normativos que intentan explicar la naturaleza del deporte. El convencionalismo considera erróneo que los juicios normativos sean derivados de «consideraciones intelectuales» y que además estén libres de la influencia que constituye el contexto social en la formulación de tales juicios. En términos epistemológicos y hermenéuticos podemos decir que la base de tales juicios no puede ser simplemente la «razón pura», esto es, una razón que se sostiene en ella misma, que, como la res cogitans cartesiana, cree estar exenta de la vida (contra lo cual Nietzsche y después Ortega y Gasset (2000) proclaman una razón arraigada en la vida, en los instintos básicos, una razón vital, Vernunft im Leben, Nietzsche, 2005), sino una razón impura que se sabe arraigada en la facticidad de la experiencia (Conill, 2006), una razón que, alejada ya del ideal ilustrado, encuentra el origen de la razón en elementos que la propia razón considera irracionales. Es una polémica en torno a los fundamentos y el carácter de los juicios que se realizan sobre el deporte. Morgan considera que tales juicios no serían posibles sin el contexto social.

$\mathrm{El}$ internalismo, aunque retoma una parte del planteamiento formalista - aquella que explica el indispensable papel que juegan las normas constitutivas que conducen a cada deporte a mayor perfección (Morgan, 2012: 65)-, se caracteriza por considerar que la fuerza de los argumentos no deriva en modo alguno de algo que pueda encontrarse en la sociedad en la que son formulados, sino que emana únicamente de su «cualidad» (Morgan, 2012: 67). Sostiene que los juicios normativos en torno a la naturaleza del deporte «son independientes del contexto social e histórico» (Morgan, 2012: 67) Sólo la «fuerza intelectual» hace de un argumento correcto o incorrecto, válido o inválido. Esta posición presupone que tales argumentos gozan de una base racional independiente del contexto histórico, social o cultural. El internalismo intenta evitar el relativismo cultural como posición que afirma que todos los argumentos tienen la misma validez, esto es, que los argumentos formulados por individuos de distintas culturas no pueden ser superiores los unos a los otros, el historicismo y otras clases de posiciones filosóficas que han criticado el ideal kantiano de una razón pura. Morgan considera que el internalismo cae en una abstracción al comprender de este modo la naturaleza de los juicios en torno al deporte.

La propuesta de Morgan consiste en reconsiderar el papel que las convenciones sociales juegan en el fundamento en el que se basan los juicios normativos para explicar la naturaleza del deporte (Morgan, 2012: 70). 
En este sentido, se distancia claramente del broad internalism de Simon o internalismo en sentido amplio. Un gran número de posiciones filosóficas han intentado defender la importancia del contexto histórico en la formulación de argumentos que pretenden ser racionales. El «peculiar nosotros» del que habla Bernard Williams es el individuo cuya visión del mundo está condicionada por su cultura, por la religión predominante en su sociedad, por los valores morales en que ha sido educado, etcétera. Morgan se aproxima a esta oposición.

En la colección de trabajos que Morgan publicó bajo el título Ethics in Sport se incluía una contribución de Simon. Morgan se ocupa de comentar, alabando y criticando al mismo tiempo, la posición internalista de Simon. Morgan considera que el internalismo es la teoría normativa del deporte más importante de los últimos tiempos, es la más sólida del entre las propuestas filosófico-normativas. Toma las virtudes de éstos y pretende desprenderse de sus errores, aunque el internalismo, a juicio de Morgan, debe ser corregido. Entre los objetivos de Morgan se encuentra la realización de tal corrección, gracias a lo cual se pueda explicar la naturaleza y fines del deporte no ya desde un punto de vista internalista, sino desde la perspectiva que Morgan denomina «convencionalismo». Ésta es una posición que se diferencia de la antigua defensa del «Ethos of games» de D’Agostino. Morgan pretende superar algunas de las fallas fundamentales del internalismo. Sobre todo su concepción de la argumentación racional y de cuáles deben ser los elementos a tener en cuenta para explicar las condiciones de posibilidad del deporte. Se propone, al mismo tiempo, criticar y superar los argumentos contrarios, como los defendidos por posiciones escépticas, relativistas o etnocentristas en el ámbito del deporte. Por ejemplo, si las reglas de un deporte han sido elaboradas en un contexto social particular, parece entonces que éste no puede ser explicado sin contar con el origen histórico de esas reglas, el cual no es otro que el que ha tenido lugar en la sociedad en cuestión. Es decir, si queremos explicar el por qué existen estas reglas y no aquellas en un deporte debemos hacer referencia a cómo se han originado socialmente, que es lo mismo que decir cuál ha sido su origen histórico. En este sentido, no es posible explicar los componentes de un deporte sin hacer referencia a cómo ha sido socialmente posible su configuración. En otros ámbitos como la filosofía de la ciencia la apelación a los elementos sociohistóricos para la explicación de las teorías científicas, y no solo a los elementos «racionales» y «lógicos», el grado de contenido empírico que posee, su capacidad de predicción y otras variables que la «lógica de la investigación científica» ha considerado determinantes para entender cómo se produce el cambio de unas teorías por otras e incluso las revoluciones científicas, ha supuesto también el inicio de nuevas concepcio- 
nes de las teorías científicas. En el caso de la filosofía del deporte, el convencionalismo ha constituido frente al internalismo, un giro bermenéutico, como el que ha tenido lugar en el ámbito de la metafísica (Heidegger) y filosofía del lenguaje y la epistemología (Wittgenstein, Gadamer, Derrida, Rorty) o el giro aplicado en ética (Karl-Otto Apel, Adela Cortina).

Morgan critica la filosofía postanalítica y el neopragmatismo junto a la idea cartesiana y kantiana de sujeto, que han recuperado tradiciones de pensamiento contemporáneas y que otras filosofías, como el relativismo cultural, han criticado. Basándose en el hecho de existen múltiples culturas y que en cada una de ellas lo racional es entendido y configurado de un modo, la idea de una base racional de la que todo sujeto participa se ha venido abajo. El sujeto posmoderno es el sujeto aislado, desquebrajado, sin un fundamento, frente a ese sujeto moderno que está seguro de sí mismo, tiene certeza con respecto a su existencia y puede basar en ello el conocimiento científico. La racionalidad de dicho conocimiento, depende, por tanto de la racionalidad propia del sujeto.

Considerar la idea internalista de racionalidad como errónea o necesariamente susceptible de corrección, no significa que debamos situarnos en una posición completamente opuesta a ella. La idea que según Rorty (1979: 38) se origina biográfica, histórica y socialmente en el período en que se inicia la filosofía moderna con la obra de Descartes y Kant, es uno de los núcleos del internalismo. Si no existieran razones de peso para defender tal idea el internalismo tendría que reconocer que el convencionalismo es una posición acertada. Por tanto, el internalismo necesita de un fundamento epistemológico sólido, en este sentido el internalismo se aproxima en extremo al positivismo filosófico y científico, que considera que la racionalidad y la explicación tiene su propia lógica, y que existen elementos «extracientíficos» que deben ser excluidos para comprender correctamente la naturaleza de las teorías científicas. El positivismo considerar que la única clase de conocimiento genuino es el conocimiento científico, que se obtiene mediante la experiencia y es matematizado posteriormente. La fuente de conocimiento es la experiencia, por tanto dota al conocimiento de un carácter eminentemente empírico que posteriormente es tratado. A pesar de su otra denominación «interpretativismo», el internalismo se encuentra muy lejos de la hermenéutica filosófica y de la idea de que la comprensión, en términos heideggerianos, es lo que hace el ser humano por el mero hecho de existir, así como de que dicha comprensión no es equiparable al conocimiento que se obtiene a través de la experiencia. La idea de una base racional que pertenece a todo ser humano sea cual sea su contexto cultural, histórico y social ha sido y es uno de sus núcleos principales en torno a la que han debatido y debaten las doctrinas filosóficas, siendo uno de los supuestos principales del in- 
ternalismo que sirve para proponer un modelo de comprensión del carácter y objetivos de esa actividad humana que es el deporte.

Morgan distingue, siguiendo a Simon, entre una internalismo en sentido amplio (o fuerte) y un internalismo en sentido débil (narrow internalism). Simon había señalado que la posición de algunos formalistas es idéntica a la del internalismo débil. Morgan considera que el internalismo fuerte constituye un avance teórico sobre el internalismo débil, por eso también cree que el formalismo ha sido superado por el internalismo fuerte. En el artículo citado expone con profusión algunas de las principales virtudes del internalismo que defiende Simon, esto es, el internalismo fuerte. Morgan subraya que esta clase de formalismo, como su propio nombre indica, amplía el horizonte de la investigación normativa sobre el deporte, intenta centrar la investigación que trata de averiguar cuáles son sus fines y descartar cuáles no lo son, estableciendo un canon que recoja los fines del deporte, que actuarán como prescripciones para quienes quieran practicarlo. En efecto, la investigación empírica es la base de la prescripción, por eso el internalismo y el formalismo son teorías normativas. El convencionalismo de D’Agostino proponía rebasar el formalismo para explicar por qué cuando se viola el reglamento sí se practica deporte y no, se deja inmediatamente de formar parte del juego. Incluso hay acciones que son éticamente necesarias y que van directamente en contra de una o más reglas. D'Agostino denomina al conjunto de razones necesarias para incumplir el «ethos of games», que son convenciones que se adoptan en el transcurso del juego con las cuales el reglamento es puesto en cuestión con el fin de que el propio deporte se practique mejor. Morgan, desde un punto de vista convencionalista pero distinto a D'Agostino, señala, contra el formalismo y tomando como referencia al internalismo fuerte, que lo que este último ha aportado a la teorización normativa del deporte es precisamente una revisión de lo que se considera sus fines. Sin embargo, Morgan cree que el internalismo sigue siendo una posición inadecuada, debido a que intentando superar el reduccionismo formalista, cae de nuevo en otra clase de reduccionismo, que no es sino el «camino abstracto» que toma para explicar el deporte.

Hemos expuesto ya algunos de los vínculos que existen en la concepción internalista del deporte y la concepción moderna de la razón. Los hemos expuesto a fin de mostrar que la crítica de Morgan tiene pleno sentido dentro del panorama filosófico contemporáneo. En este sentido, Morgan no hace sino sumarse a lo que se ha denominado filosofía posmoderna, que entiende que la razón es una idea producto de la imaginación si se la concibe como algo que comparten todos los sujetos y que es invariable histórica, social y culturalmente. La concepción posmoderna de la razón no es unívoca. Existen distintas interpretaciones 
que pertenecen todas ellas a ese rótulo por tomar como punto de partida a una crítica de la idea moderna de razón. Dentro de este grupo, además de los ya mencionados, se incluiría, por ejemplo, la primera Escuela de Fráncfort. Obras como The Eclipse of Reason (Horkheimer) o Dialéctica de la Ilustración (Horkheimer y Adorno) representan una línea propia dentro de las filosofías críticas de la idea moderna de razón. Morgan toma como referencia a esta clase de crítica para descubrir en la explicación internalista del deporte un error fundamental. Tan solo resta, por nuestra parte, extraer algunas de las consecuencias de esta crítica que tienen conexión directa con el deporte. Si hemos destacado dicha crítica era para mostrar que en modo alguno Morgan puede ser considerado internalista, pues discrepa con una de sus ideas nucleares. Argumentamos así, como habíamos prometido, contra lo que algunos autores han defendido, en particular, que la posición de Morgan puede ser considerada como «convencionalismo internalista».

Entre dichas consecuencias que entroncan directamente con el problema del deporte se encuentra que el convencionalismo internalista defendido por Morgan trata de explicar esta práctica humana asumiendo que nace y se desarrolla en contacto con los valores, normas y aspiraciones de la sociedad. ¿Cómo comprender los fines del deporte al margen de la constitución histórica del mismo? El problema de los fines, que es uno de los más importantes que Morgan examina en su revisión del internalismo, no puede ser planteado sin tener en cuenta el hecho de que, a diferencia de lo que había creído D'Agostino, las correcciones que pueda hacerse a las reglas del deporte durante el transcurso de la práctica de éste pueden ser consideradas necesarias, no porque apelen a un «ethos del juego», sino por razones que conectan precisamente con la crítica filosófica posmoderna. Afirma que las dos condiciones fundamentales que debe cumplir toda teoría normativa «son problemáticas», y ello porque:

...volar a una altitud tan reflexiva es contraproducente porque (...) nos encontramos demasiado lejos de los contextos sociales e históricos, en los cuales llevamos a cabo colectivamente en nuestras respectivas prácticas comunitarias el propósito de esfuerzos como el deporte y generamos las razones que llegamos a sostener al perseguirlos, que son tanto accionesguías o motivaciones (Morgan, 2012: 71).

\section{Conclusiones}

En estas conclusiones nos proponemos sintetizar diferencias y semejanzas entre la posición de D’Agostino y la de Morgan que hemos puesto de manifiesto a lo largo del trabajo. 
Por un lado, D'Agostino concibe a las convenciones como un elemento moral presente intrínsecamente en el desarrollo de la práctica deportiva, a pesar de que en ocasiones no sea reconocido como tal o que se ignore por los deportistas e incluso por los árbitros por razones legales o simplemente por malversación. Pone el acento sobre el hecho de que, frente al formalismo, hay que rechazar la concepción del deporte que lo asocia a una práctica que se atiene siempre a las reglas establecidas previamente al desarrollo de dicha práctica. Uno de los argumentos fundamentales de Morgan contra la concepción formalista del deporte afirmaba, como vimos, que también hay deporte cuando las reglas son violadas por mor de una necesidad moral, necesidad sobre la que todos los jugadores están de acuerdo a pesar de que en las circunstancias concretas en que se plantea la objeción moral a las reglas deportivas no la acepten (debido a que su único objetivo es conseguir lo que las reglas formales dicen que es el fin de la práctica deportiva; a saber, vencer).

Por otro lado, Morgan también considera que las convenciones pueden ser elementos morales. Sin embargo, su crítica al formalismo es distinta a la de D'Agostino. Para Morgan, el formalismo no sólo es reduccionista, sino que tampoco dispone de una capacidad explicativa adecuada de los componentes morales del deporte. Es decir, no solo reduce la naturaleza del deporte a lo que las reglas dicen, sino que tampoco (quizá a causa de aquello) puede explicar ni justificar la existencia de elementos morales en el deporte tales como los valores o los ideales. Precisamente en este sentido tenemos que entender su afirmación según la cual el formalismo, para explicar los valores morales y otras elementos éticos en deporte, tiene que eliminar el propio carácter moral de éstos (Morgan, 2004: 163), lo cual significa que de destruye lo que hace que sean valores morales y no valores económicos, políticos o sociales. El formalismo, en consecuencia, no dispone de una capacidad explicativa adecuada con la que dar cuenta normativamente (puesto que todas las posiciones que debaten sobre este problema adoptan enfoques normativos; Morgan, 2005: 162) de los valores, principios o convenciones morales:

Uno de los problemas más importantes que surgen en la explicación formalista del deporte es que muchas de las cuestiones éticas que surgen en el deporte no pertenecen al ámbito las reglas formales (Morgan, 2004: 162).

En este punto, como se deduce de lo expuesto en el trabajo, coinciden D'Agostino y Morgan. 


\section{REFERENCIAS}

-Brohm, J. (1992). Sociologie politique du sport. Nancy: P.U.N.

-Cortina, A. (1990). Ética minima. Madrid: Tecnos.

-Cortina, A. (1993). Ética sin moral. Madrid: Tecnos.

-Cortina, A. (2011). Neuroética y Neuropolítica. Sugerencias para la educación moral. Madrid: Tecnos.

-Cortina, A. (2014). Deporte y juego sucio. El País (sábado 1 de febrero).

-Conill, J. (2006). Ética hermenéutica. Madrid: Tecnos.

-Conill, J. (2008). Hermenéutica crítica desde la facticidad de la experiencia. Convivium (21), 31-40.

-D'Agostino, F. (1981). The Ethos of Games. Journal of the Philosophy of Sport (14), 1-20.

-D’Agostino, F. (2013). The Orders of Public Reason. Analytic Philosophy, 54 (1), 129-155.

-Domingo Moratalla, A. (2014). Las deudas de las Éticas Aplicadas con la hermenéutica dialógica. De Gadamer a Ricoeur. En I. Murillo, La filosofía práctica (págs. 94-95). Madrid: Ediciones de Diálogo Filosófico.

-Fraleigh, W. P. (2003). Intentional rules violations. One more time. Philosophy of Sport, 30 (2), 166-176.

-Fraleigh, W. P. (1984). Right Actions in Sport. Ethics for Contestants. Champaign: Human Kinetics.

-Gadamer, H.-G. (1977). Verdad y método. (Vol. I). Salamanca: Sígueme.

-Gadamer, H.-G. (1993). Verdad y método (Vol. II). Salamanca: Sígueme.

-Kant, I. (2003). Fundamentación de la metafísica de las costumbres. Madrid: Encuentro.

-Lipovetsky, G. (1994). El crepúsculo del deber: La ética indolora de los nuevos tiempos democráticos. Barcelona: Anagrama.

-Lipovetsky, G. (2011). El imperio de lo efimero: La moda y su destino en las sociedades modernas. Barcelona: Anagrama.

-Macnamme, M. (2007). Sport, Ethics and Philosophy: Context, History and Prospects. Sports, Ethics and Phylosophy (1), 1-6.

-Morgan W. (2002). Social Criticism as Moral Criticism: A Habermasian Take on Sports. Journal of Sport and Social Issues, 26 (III), 281-299.

-Morgan, W. (2004). Moral Antirealism, internalism, and sport. Journal of de Philosophy of Sport (31), 161-163.

-Morgan, W. (2012). Broad internalism, deep conventions, moral entrepeneurs, and sport. Journal of the Philosophy of Sport (39), 65-100.

-Morgan, W. (2013). Games, rules, and conventions. Philosophy of the Social Sciences, $20(\mathrm{X}): 1-19$.

-Macnamme, M. (2007). Sport, Ethics and Philosophy: Context, History and Prospecs. Sports, Ethics and Phylosophy (1): 1-6.

-Nietzsche, F. (2005). El crepúsculo de los idolos. Madrid: Alianza.

-Ortega y Gasset, J. (2000). El tema de nuestro tiempo. Madrid: Alianza.

-Pérez Triviño, J. L. (2012). Ética y deporte. Bilbao: Desclée de Brouwer. 
-Pérez Triviño, J. L. (2013a). La filosofía del deporte: Un panorama general. Fair Play. Revista de Filosofía, Ética y Derecho del Deporte, 1 (1), 4-26.

-Pérez Triviño, J. L., (2013b). La aplicación de normas en el Derecho y en el deporte: jueces y árbitros. Revista española de derecho deportivo (32), 83-106.

-Simon, R. L. (2000). Internalism and internal values in sport. Journal of the Philosophy of Sport, 27 (1), 1-16.

-Simon, R. L. (1991). Fair Play: The ethics of sport. Boulder CO: Westwiew Prest.

-Wittgenstein, L. (2011). Investigaciones filosóficas. Barcelona: Crítica.

Sumario: Introducción. El convencionalismo ético en deporte; 1. El êthos del juego como conjunto de convenciones según Fred D’Agostino; 2. El convencionalismo internalista de William Morgan; 2.1. Entre convencionalismo e internalismo; 2.2. Una precisión necesaria; 2.3. Internalismo y convencionalismo; Conclusiones; Referencias. 